\title{
(6) OPEN ACCESS \\ FIGO's ethical recommendations on female sterilisation will do more harm than good: a commentary
}

\author{
D A A Verkuyl $\left.\right|^{1,2}$
}

${ }^{1}$ Refaja Hospital, Obs \& Gyn Department, Stadskanaal and ${ }^{2}$ CASA Klinieken, Leiden, The Netherlands

Correspondence to Dr D A A Verkuyl, Leinweberlaan 16 3971 KZ, Driebergen, The Netherlands; verkuy|@freeler.n|

Received 10 September 2013 Revised 30 May 2014 Accepted 12 June 2014 Published Online First 9 July 2014

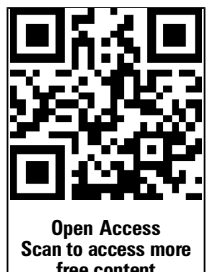

CrossMark

To cite: Verkuyl DAA. J Med Ethics 2015;41: 478-487.

\section{ABSTRACT}

The International Federation of Gynecology and Obstetrics (FIGO) Committee for the Ethical Aspects of Human Reproduction and Women's Health advises against tubal occlusion (TO) performed at the time of caesarean section (CS/TO) or following a vaginal delivery (VD/TO) if this sterilisation has not been discussed with the woman in an earlier phase of her pregnancy. This advice is neither in accordance with existing medical custom nor evidence based. Particularly in less-resourced locations, adherence to it would deny much wanted one-off sterilisation opportunities to hundreds of thousands of women, many of whom have no reliable contraceptive alternative. To be sure, a well-timed discussion in pregnancy about a potential peripartum TO is preferable and, if conducted as a matter of course (as the Committee appears to promote), would represent an enormous improvement on current practice. Earlier counselling has the advantage that it results in fewer women who regret having rejected the CS/TO or VD/TO option. However, there is no evidence that earlier counselling leads to a smaller proportion of regretted sterilisations. Consequently, where early TO counselling has been impossible, forgotten or deliberately omitted on pronatalist, traditional, financial, cultural or religious grounds, offering a perinatal sterilisation belatedly and in an unbiased, culturally sensitive manner is often verifiably better than not presenting that option at all, notably where high parity and uterine scars are particularly dangerous. Belated counselling, as will be demonstrated in this paper, saves many lives. The Committee's blanket rejection of belated counselling on perinatal sterilisation is therefore unjustified.

\section{INTRODUCTION}

There are clear motivational, logistic, economic and medical advantages to providing tubal occlusion (TO) services during a caesarean section (CS/ $\mathrm{TO})$ or soon after a vaginal delivery (VD/TO). However, the peripartum period is deemed a poor time to make important decisions-women are vulnerable, dependent on medical care, in pain and more easily pressured.

In an ideal world, counselling about the option of a sterilisation during a CS or soon after delivery, even in the absence of specific reasons to expect a CS, should therefore first take place weeks before birth, preferably by the doctor who would be in attendance should a CS turn out to be the mode of delivery. However, many pregnant women have no access to early counselling, let alone to a counsellor with the authority to 'grant' a desired TO, because they only see a doctor/obstetrician late in pregnancy, after an-often medically indicatedtransfer from home or a (remote) clinic. This makes early counselling, as opposed to giving information, by a midwife or nurse (-aid) who often provide the antenatal care, somewhat irrelevant. Yet, many women would stand to benefit from the often unique opportunity to reliably stop having children a peripartum TO provides. Not infrequently, the operation might save their lives by preventing future unintended risky pregnancies. However, a report about contraceptive sterilisation by International Federation of Gynecology and Obstetrics (FIGO) Committee for the Ethical Aspects of Human Reproduction and Women's Health discourages belated counselling (ie, not long before a CS or while still admitted after a VD) under all circumstances. The report contains, inter alia, the following recommendations: ${ }^{1}$

- '...consent to sterilization should not be requested when women may be vulnerable such as when requesting termination of pregnancy, going into labor, or in the aftermath of a delivery.'

- 'Sterilization for prevention of future pregnancy cannot be ethically justified on grounds of medical emergency. Even if a future pregnancy may endanger a woman's life or health, she will not become pregnant immediately, and therefore must be given the time and support she needs to consider her choice.'

This guidance, which often makes sense for those women who can reliably prevent unintended pregnancies without TO and who give birth in very favourable circumstances, makes no provisions for the hundreds of millions who do not.

\section{INCONSISTENCY WITH EXISTING MEDICAL PRACTICE}

In many medical situations, lack of stress or pain is no prerequisite for giving patients a choice. Decisions about vascular stents, anticoagulation, hip fractures, induced or spontaneous abortions and instrumental (vacuum or forceps) deliveries are nearly always taken under stress. During delivery, women are routinely asked to consent to a CS, which carries an estimated mortality of $0.5 \%-2 \%$ in some less-resourced locations (LRL) ${ }^{2}{ }^{3}$-higher if uterine scar-related complications in subsequent (not seldom unintended) pregnancies are counted. Women in labour (and apparently obstetriciansCS rates vary tenfold (7\%-70\%, average 33\%) among US hospitals) ${ }^{4}$ are typically unable to accurately assess the need for a CS, while fear, costs and the prospect of pain relief will influence their 
judgement. But according to FIGO's Committee, these same women should, if they have not been counselled earlier, be denied the option of a concurrent TO, even when future pregnancies would entail a considerable risk to their health and when women (couples) assure the doctor that they certainly do not want any more children and that it is not a spur-of-the-moment decision. This notwithstanding that performing a TO at the time of a CS neither increases surgical risk nor affects the amount of pain suffered, and in disregard of the fact that most women understand the implications of putting an end to their fertility much better than the immediate and long-term risks and benefits of having a CS. Unlike situations where patients are forced to make unexpected critical decisions about vascular stents, anticoagulation or hip fractures, the potential completeness of the family is contemplated by many couples for months prior to the possible implementation of a perinatal TO. Many women hoped one to four pregnancies ago already that their family was complete but they lacked thedependable-means to realise this wish. ${ }^{5}$

It is true that, while many women would benefit from being given - be it early or belatedly - the option of sterilisation to be implemented around the time of delivery, a minority will end up regretting a TO. But this kind of cost-benefit calculation is routine in medical practice and indeed in daily life. For example, anticoagulants are prescribed to people deemed to be at high risk of dangerous blood clots, even though the medication will cause fatal haemorrhages in a minority, and sometimes seat belts or an antibiotic allergy prove fatal.

\section{WHAT IS THE EVIDENCE?}

The Committee does not make it clear why exactly it objects to belated counselling. The Committee might disapprove because belated decisions could open the door, and perhaps the slippery slope, to unscrupulous doctors who do not have their patients' best interest at heart, but their own agenda. Addressing the scruples would seem to be the priority. It is likely that the Committee is understandably worried that women choosing a TO under stress, even if they were counselled as properly as the circumstances allowed, more frequently regret their TO later. This paper questions this assumption, there is much evidence to the contrary, and even if we had such data-the Committee does not provide references-it would not follow that the longterm consequences of belated counselling will in all plausible scenarios be worse than not offering women the option of being sterilised at all. The Committee's concern might (also) be that belated counselling in stressful circumstances can compromise the autonomy of the choices made. This point of view is related to a rather specific cultural background while the Committee makes recommendations for the whole world. In a diverse global arena, utilitarian/consequentialist practical calculations are the considerations most commonly shared. It follows that this contribution will emphasise the evidence-based, practical consequences of the Committee's recommendations, also as reflected in morbidity and mortality data.

A follow-up study in Zimbabwe of women who had delivered three or more times and who were, with respect to their most recent delivery, either not counselled about TO or belatedly provided with the peripartum TO option resulted in 1533 respondents with an average of 5.3 children. ${ }^{5}$

Of the women who underwent sterilisation, $1.8 \%$ (18/973) subsequently regretted doing so, whereas $47.7 \%$ (267/560) of those who were not sterilised regretted missing the opportunity. Notably, regret was thus 26 times more frequent among women who had not been sterilised than among those who had been.
Of the 267 women who regretted not having a TO, 174 did not have it because this option had been withheld and 93 regretted declining a TO. Women who underwent a TO and regretted it mostly did so following the AIDS-related death of a partner and/or child in an era when there was little access to anti-HIV medication. Earlier counselling would probably not have prevented these regrets. Repair of the Fallopian tubes was offered at no costs, including reimbursement of travel expenses, to the 18 women who regretted their TO but, ultimately, once the results of the HIV tests were known, only one $\mathrm{HIV}^{+}$widow, tested on condition that she would not be informed about the result, opted for tubal reconstruction. If one only considers regrets strong enough to submit to a free tubal repair attempt, the frequency of regret is no longer 26 times but 468 times greater among women who were not sterilised than among those who were. ${ }^{5}$

In reality, the decision facing doctors is not $\mathrm{TO}$ or no TO, but rather, to offer or not to offer women the TO option. The results of the Zimbabwe study have much to say about this :

- When a CS/TO was offered belatedly, around the time that an unscheduled CS seemed indicated, 10\% (30/301) of women expressed regret at follow-up- $80 \%(24 / 30)$ of these regretted declining the TO option, and six women regretted undergoing it. When a TO was not offered under these circumstances, $65.8 \%$ (77/117) of women regretted the missed opportunity.

- When a CS/TO was offered somewhat earlier (though obviously not early enough for FIGO's Committee), typically the day before at the antenatal clinic or ward or after referral from a district or mission hospital, 4.3\% (15/346) of women regretted their decision of whom a third regretted declining a TO and two-thirds (10/15) regretted accepting it. Of the patients in this 'elective' CS group not counselled about the TO option, $65 \%(13 / 20)$ regretted not having a TO.

- Of the patients offered a VD/TO -all unethically late according to the Committee, that is, typically during postnatal ward rounds-11.2\% (66/590) had regrets of whom $64 / 66(97.0 \%)$ regretted declining. Of those not offered a $\mathrm{VD} / \mathrm{TO}, 84 / 159$ (52.8\%) regretted not having had one.

Later CS/TO counselling led to more regretted declinations $(8.0 \%)$ than somewhat earlier counselling $(1.4 \%, \mathrm{p}<0.001)$. There was no evidence that later counselling increased the rate of regretted TOs. Many regretted VD/TO and CS/TO rejections were related to the fact that women could not consult their husbands (ambulance full, employed elsewhere, no lodging facilities, transport too expensive). Wider spread availability of cell phones has no doubt improved this situation since (see box 1 , for the maternal mortality implications).

A Dutch retrospective cohort study of women who had delivered at least twice and undergone a CS at least once yielded 498 respondents (96.7\% follow-up rate), on average 3 years after delivery. It found that 62-186 times more women would experience regret after being denied the TO option than after having been offered it. It revealed no evidence that offering a TO belatedly led to more regretted TOs. However, like the Zimbabwe study, there were clear indications that belated counselling increased the risk of regretted TO rejections. ${ }^{6}$

In the USA, for publicly-funded (Medicaid) perinatal TO, a 30-day waiting period is required between the time of consent and the TO. In cases of emergency CS and/or premature delivery, this stipulation may be waived, but a minimum $72 \mathrm{~h}$ delay is still required. These regulations were implemented (1978) to prevent TO after pressure and uninformed consent, but there is strong evidence that they 'may not, in fact, ensure that consent is truly 
informed'. They do, however, 'prevent many low-income women from getting a desired sterilization procedure'. ${ }^{8} \mathrm{~A}$ review of the literature found no evidence that the delay requirement 'has prevented sterilization abuses or poststerilization regret', while recognising 'that these associations are difficult to assess' . It is has been estimated that removing these barriers for women desiring publicly funded sterilisation in the USA could prevent annually over 10000 abortions, 19000 originally unintended births and lead to cost savings of $\$ 215$ million each year. ${ }^{9}$ Of course, in the USA, abortions are safe and although Medicaid stops paying, also for contraception, 6 weeks after birth, the next delivery will be, unlike those of most women in LRL, specialist supervised. Removing the long waiting period stipulation and

Box 1 Consequences of not giving women a belated TO choice

Hypothetically, if all 1533 women in the study, ${ }^{5}$ following FIGO's advice, would not have had the TO choice the following could have occurred:

- The 93 women who in the real study regretted declining a TO would still lament their open tubes, just like the 174 women who regretted being denied the TO option; women happy with their TO (955) in the real study would presumably be unhappy. Total: 79.7\% (1222/1533) unhappy.

- Conversely, if all 1533 had been given the belated TO option, ignoring FIGO's recommendation: Then the above 93 would be unhappy, as would the 18 women who regretted their TO in the real study; perhaps $15 \%$ of the above 174, 26 , would have declined a TO at the crucial hypothetical juncture and regretted it later; let us assume that of the 124 women happy after being denied the TO option in the real study, five would have accepted the hypothetical peripartum TO option by mistake because of the stress-FIGO's fearand came to regret that later. Total: $9.3 \%(142 / 1533)$ unhappy.

- The maternal mortality rate in SSA is at least $1: 300^{17}$ and probably nearly twice that for a group of mostly low income women, generally older than 30 years, with at least three children -on average 5.3- who consider their family complete, live in a country where abortions are mostly illegal and of whom more than $50 \%$ has at least one scar in the uterus.

Therefore, it can be calculated, assuming that women without TO will, with the prevailing access to reliable reproductive services in SSA, have on average 1.5 more deliveries - an underestimation, in one Texas study $47 \%$ of those who had missed an intended peripartum TO opportunity because of red tape were pregnant within a year ${ }^{52}$ that offering all 1533 the perinatal TO option, as opposed to heeding FIGO's advice and providing none with this choice, would result in 1126 TOs $(973+148+5)$ and prevent 10 maternal deaths and around 1700 unintended children (perhaps 100 HIV infected, and twins included), 170 miscarriages and 100 abortions for the price of 23 regretted TOs.

- Crucially, many (or all) of the 23 regretted TOs would also have occurred if FIGO-approved earlier counselling had been possible, and indeed performed, because most regrets are caused, if the women were not pressured, by unanticipated events developing after delivery.

See 'What is the evidence?' section. associated bureaucratic misunderstandings, and simultaneously employing part of the above millions for IVF treatment for selected cases seems an excellent option.

In Brazil, the world's CS/TO champion, the government's total prohibition of $\mathrm{VD} / \mathrm{TO}-$ not difficult to enforce-has led to an enormous increase in the number of CS/TO. Because women are so eager to have a perinatal TO, many undergo unnecessary CSs. Under many circumstances, CS/TO is also illegal in Brazil—complicated to police-and so the TO component is often paid for surreptitiously by the couple and not recorded in the medical records. ${ }^{10}$ Increasing access to male and interval (ie, unrelated to delivery, extra uterine pregnancy or miscarriage/abortion) sterilisation and long acting reversible contraception and permitting VD/TO and CS/TO but making payment for the TO component (5 min work) of CS/TO illegal would very likely improve the quality of counselling and reduce Brazil's dangerously and expensively high CS rate (see box 2) somewhat.

\section{WELL-TIMED STERILISATION COUNSELLING IS OFTEN UNAVAILABLE}

In 2009, 22\% and 30\% of women in sub-Saharan Africa (SSA) and Southern Asia, respectively, delivered unbooked-that is, without having been seen even once prior to delivery by healthcare providers. ${ }^{11}$ This is compounded by the fact that a postnatal visit-routine in rich countries around 4-6 weeks after birth when delivery, health and breast feeding are evaluated and contraception discussed/provided/organised-is rare for the poor in large regions of the world.

Being unbooked can be related to poverty, large distances, lacking the husband's permission, women being not allowed to travel alone, bad experiences, abandoned health facilities, security situation, washed away bridges and so on. The costs of seeing a doctor result in more malnutrition for the children of subsubsistence farmers and slum dwellers. Being unbooked often implies that there are also barriers for obtaining reliable contraception after delivery. Many women only go to hospital, perhaps via a clinic, when labour becomes abnormal and in some regions a delay of hours routinely ensues because a CS will only be performed if the family can scrounge enough money to buy soap, cotton wool, antibiotics, a catheter and sometimes blood. There are many SSA hospitals where 2\%-5\% of the foeti are dead by the time an emergency CS is started.

A study from a rural Nigerian Baptist hospital with a 39.8\% institutional CS rate found that $86 \%$ of CS/TOs involved women who had already delivered earlier at least four times $($ Para $\geq 4)$ and $14 \%$ who were Para 3 . Only $38 \%$ of women who underwent a peripartum TO were booked; therefore, at least $62 \%$ were counselled belatedly. ${ }^{12}$ Nigerian women, not only in the North, are frequently denied access to contraception, resulting in many unintended pregnancies and maternal deaths. ${ }^{13}$

\section{FEMALE STERILISATION IS POPULAR}

Globally, $18.9 \%$ of women aged $15-49$ who are married or living in union have undergone a $\mathrm{TO}-\mathrm{a}$ third of all modern contraceptive users. ${ }^{14}$ This figure is $23.6 \%$ for the USA, and around 50\% of American women aged 35-44 years and more than $60 \%$ of all US women with two or more children rely on male or female sterilisation for contraception. ${ }^{14}{ }^{15}$ Half of female sterilisations in the USA are either a CS/TO or a VD/ TO. ${ }^{6}$ In Brazil, 5.1\% of men and 29.1\% of women (more than $70 \%$ of female sterilisations were combined with a CS $)^{10}$ living as couples are sterilised. ${ }^{14}$ In SSA, these figures are $<0.1 \%$ and $1.6 \%$, respectively. ${ }^{14}$ Sub-Saharan women aged $35-44$ have on 


\section{Box 2 Selected reproductive data}

- Among the 208 million women estimated to become pregnant worldwide, $59 \%$ (or 123 million) experience a planned (or intended) pregnancy leading to a birth or miscarriage or a stillbirth. The remaining $41 \%$ (or 85 million) of pregnancies are unintended, and 45 million of those ended in an induced abortion. ${ }^{26}$ The number of unsafe abortions was estimated at about 22 million in 2008 and is increasing. The proportion of all abortions that are unsafe has increased from $44 \%$ in 1995 to $49 \%$ in 2008 . Almost all unsafe abortions occur in developing countries. Abortion rates per 1000 women in developed countries are falling, and rates (but not the numbers in absolute terms) are stable in developing countries. Because of increased contraceptive use, the pregnancy rate worldwide has fallen from 160 pregnancies per 1000 women aged 15-44 years in 1995 to 134 per 1000 women in $2008 .{ }^{26}$ Globally, of the married women, 191 million (222 million if unmarried women are also counted) have an unmet need for modern contraception. Contraception probably prevented 270000 maternal deaths in 2008, and meeting the unmet need for contraception could prevent another 100000 deaths per year. ${ }^{53}$ There were estimated to have been 293000 maternal deaths in $2013 .^{31}$ Under the prevailing circumstances a girl entering puberty in Chad has an one in eight chance of dying of a future pregnancy, in Scandinavia one in 18000 .

- Globally, there are about 18.5 million CS annually (around $15 \%$ of all deliveries). Best estimates of selected national CS rates from different sources: Australia 30.3\%, China 25.9\%$42 \%$, India $8.5 \%$, Bangladesh 7.5\%, Philippines $9.5 \%$, Iran $41.9 \%$, Iraq $32 \%$, Syria $15 \%$, Egypt $27.6 \%$, Ethiopia $1 \%$, Nigeria $1.8 \%$, Chad $0.4 \%$, Swaziland $7.9 \%$, Zimbabwe $4.8 \%$, South Africa $21 \%$, Kenya $4.0 \%$, Mexico $37.8 \%$, Brazil $45.9 \%$, Spain $25.9 \%$, Ireland $26.2 \%$, France $18.8 \%$, Scandinavia $16.3 \%-21.4 \%$, Russia $18 \%$, Poland $16.1 \%$ and Rumania $23.6 \%$. Often, these national rates hide large differences between rich and poor and urban and rural. WHO claims that for optimal results the rates should be between $5 \%$ and $15 \%$. In low and middle-income countries, the provision of CS is handicapped by a severe lack of equipment and well-trained staff. ${ }^{54}$

- The UN Population Division expects in its "High Variant" the populations of Burundi, Malawi, Mali, Niger, Nigeria, Somalia, Uganda, Tanzania and Zambia to increase at least seven-fold between 2015 and 2100. In its "Constant-fertility Variant" a more than eighteen-fold increase is expected. ${ }^{55}$

average 2-3 times as many children as their North American, European, Turkish, Iranian, Thai, Tunisian, Bangladeshi, Japanese, Korean, Australian, Chilean and Brazilian counterparts. Why should the Committee encourage bending over backwards to prevent a possible but unproven increased TO regret rate following belated counselling, when relevant studies demonstrate high having-missed-a-TO regret rates among mothers of several children who were denied belated counselling?

This question is particularly pertinent for communities that are seriously threatened by land hunger, decreasing soil fertility, poverty, environmental degradation and insurgency related to rapid population growth, that is, demographic entrapment. Presently, thousands die already while fleeing poverty. There are a hundred million moderately and severely underweight children in SSA, and population increase (see box 2) and possibly climate change will likely depress per capita food consumption still further. ${ }^{16}$ Globally, $45 \%$ of all deaths of children younger than 5 years may be related to undernutrition. ${ }^{17}$

Naturally, for prosperous countries it is also important to prevent unintended pregnancies. Their citizens' disproportionate life expectancy and consumption patterns affect the poor via rising food, fertiliser, land and fuel costs; deforestation; and $\mathrm{CO}_{2}$ production. For doctors, the low-hanging damage-limitation-fruit in rich and poor countries is trying their utmost to assist their patients to prevent unintended pregnancies. ${ }^{18} 19$

Ignoring the ethical imperative to maximise desired access to reliable contraception is the 'The Tragedy of the Committee', not unlike (ie, regulations/laws/attitudes are biased towards individual rights, rather than shared well-being and the interests of future generations, but this results tragically in (most of) those very individuals being worse off) the Tragedy of the Commons. $^{20}$

\section{THE COMMITTEE'S CONCERNS ABOUT THE POTENTIAL DANGERS OF BELATED STERILISATION COUNSELLING ARE REALISTIC FOR A MINORITY OF WOMEN, BUT THIS DOES NOT MEAN THAT THERE SHOULD BE A BLANKET BAN}

First, we should note that there is a remarkable contrast between the casual, distracted, accidental, not seldom intoxicated or (somewhat) involuntarily manner by which many pregnancies are started and the determination needed to overcome the myriad barriers present for many of those who want to reliably postpone or stop reproduction. ${ }^{21} 22$ Why is the regret of a mother of 2-7 unable to have more children so much more important than the worries of 20 times as many mothers of 2-7 who have to fear another pregnancy for the next 15 years or so? In other words, why is in these cases a regretted TO seen as so much more deplorable than the 'tyranny of excessive fertility'? Future, possibly overcrowded, generations-by the time technical advances have made infertility the default mode, while starting a pregnancy will demand more complicated technical and organisational steps-will probably wonder about this bias. It seems illogical, that is, while the overproduction of offspring used to be an absolute necessity for the emergence and survival of man-to make it possible to deselect the not so 'fit' while avoiding extinction: a very cruel mechanism - it is for some time now because of increasing life-expectancy, and per capita consumption and waste production, a hazard, also to other species.

Importantly, there is very little risk of women being coerced into an unwanted VD/TO. That would require seductive financial inducements, a police or racist state, and/or a conspiracy of the hospital staff. Under these circumstances, FIGO's ethical convictions will be irrelevant in any case, even as its recommendations may cause women in cultures with more established individual rights to forego a desired VD/TO. Moreover, a nonrelaxed patient makes the operation technically impossible if the VD/TO is performed under local anaesthesia. General anaesthesia also requires cooperation, patients have to be starved and intravenous access needs to be established. Regional analgesia also demands a drip and a non-moving actively bent-over patient for an injection between the vertebrae. Even if those hurdles could be surmounted (Auschwitz), then communities would soon protest, at least with their feet, about patients forced on the operation table the day after delivery and 'opened' against their will.

However, it is certainly true that, as the Committee states, some women are pressured into having a TO with their CS. 
Some are asked to sign, or put a fingerprint, at the bottom of a paper while the implications escape them under the circumstances. They might be lied to that a TO is a temporary contraceptive method or the medical necessity may be misrepresented or the doctor threatens not to perform the indicated CS without a concurrent TO. It may happen that women are not even informed afterwards that they had a TO. Often they are from minority groups, substance abusers, mentally and/or educationally challenged or have a serious disease. This unethical behaviour should be stopped but not by a blanket condemnation of belated counselling. It should be observed that this behaviour is seen much less frequently than healthcare providers or institutions passing up, by mistake, disinterest, incompetence or as a matter of policy, opportunities to assist women with desired contraception. $^{21-25}$ Imagine if those women would, like some of the victims of $\mathrm{CS} / \mathrm{TO}$ under pressure, also sue? And why not? Around 41\% (85 million, see box 2) of all (208 million) pregnancies worldwide are unintended ${ }^{26}$ and many of the women involved had earlier been in contact with health personnel who neglected to facilitate the use of reliable contraception, and/or politicians did not prioritise (financial) access to contraception. Moreover, denying access to desired contraception might, just like CS/TO under pressure, happen-for example, Romania 1966-1990, China under Mao, African states in the years after independence-on nationalist, religious or ethnic discrimination grounds, that is, governments, tribes or religions trying to augment a preferred group of the population or wanting more soldiers and/or influence.

It is true that in LRL, women under 45 frequently lose a child or partner, and access to TO reversal or test tube fertilisation is rare. However, many women/couples in SSA opting for a peripartum TO already have $\geq 3$ children-often one to three more pregnancies than intended, ${ }^{24}$ and it is part of the equation that the risks of another pregnancy are also much higher than those in richer countries.

A family that loses the mother following a missed TO opportunity does often very badly including much higher child mortality. ${ }^{28}$ There are already millions of orphans in SSA and a mother who regrets having 'only' three children can often take care of a child of her extended family and those children tend to do much better than in an orphanage, as a street kid or child soldier.

There is frequently a remarkable recall bias. Doctors will remember for the rest of their lives a woman who was sterilised who subsequently regretted it. Studies about regretted TOs abound; studies about the consequences of missed TO opportunities are rare. Many victims of missed TO opportunities are not even recognised as such: an unintended sixth child in a family already unable to produce enough food and/or pay the school fees; a woman who died at home of a ruptured uterus trying to deliver her fifth child; a woman seeing no other option than to arrange for herself an abortion (more than 40 million annually, half 'backstreet', box 2 ); ${ }^{26}$ a woman known to be $\mathrm{HIV}^{+}$who would—if asked-have stated that she had a completed family, whose subsequent unintended child died of AIDS after 2 years of horrible suffering. There are about 15 million HIV infected women in SSA alone and in 2011 there were 270000 new HIV infections among 0-14 year olds, notwithstanding heroic efforts during and after pregnancy to prevent mother to child transmissions. $^{29} 30$

However, by far the most effective way to prevent mother to child transmission is providing access to desired reliable contraception. ${ }^{23}$ Pregnancies also lower the immunity of women with HIV even further, even when on medication, and therefore mortality is much higher during (a factor 6) and in the years after a pregnancy. ${ }^{31}$ Hormonal contraception and HIV (medication) can interact, that is, more HIV transmission, diminished efficacy, more forgetfulness and decreased immunity.

Would it really be more unethical to discuss soon after delivery a sterilisation with a mother of three, found to be $\mathrm{HIV}^{+}$, than to refrain from discussing contraception or merely advise her to use the pill, knowing that the chances are that she will become pregnant again inadvertently (vide infra)? Moreover, many $\mathrm{HIV}^{+}$ mothers do not breast feed. While extended breast feedingbesides malnutrition-is under 'completely natural' circumstances (eg, Niger) the reason that women have on average, if they survive long enough (Niger (or perhaps Chad) has the highest maternal mortality in the world), six to eight children instead of 13.

Reports of CS/TO misuse and side-effects (regret, sometimes angry husbands), and the feeling that these sterilisations are much too convenient, encourage well-meaning people, like the Ethical Committee members, to create barriers to perinatal TO that are particularly insurmountable for the most disadvantaged, who are, admittedly, also sometimes the most vulnerable to

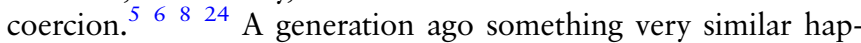
pened regarding access to injectable contraceptives, with tragic results. International action groups convinced some governments in Africa and Asia to ban this method, because the three monthly injections were sometimes administered without proper counselling (eg, to the proverbial nanny in South Africa) and they were not without side-effects. Hundreds of women with completed families, for whom these injections were the only realistic reliable contraceptive option and much less dangerous than another pregnancy, must have died as a result and thousands of families became even more impoverished. ${ }^{32}$

\section{THE RISKS OF NOT GIVING WOMEN THE OPTION OF A PERIPARTUM STERILISATION}

One must, therefore, set the risks of TO misuse and regret against the likely costs of adhering to the Committee's advice, which in LRL are considerable. Many women deliver without attending skilled health personnel $(54 \%$ in SSA and $50 \%$ in Southern Asia). ${ }^{11}$ In such conditions, scars in the uterus after a previous CS are very dangerous. In SSA, approximately one in 300 deliveries ends in an obstetric fistula ${ }^{33}$ (a difficult to repair, debilitating, emotionally devastating, hole in the bladder mostly caused by prolonged and unrelieved obstructed labour, last seen in Europe when the chaos of the World War II disrupted the medical services fundamentally), amounting to 50-100000 cases annually in all LRL combined. Scarred uteri rupture much faster than fistulae evolve. Scar ruptures are seen on nearly a daily basis in some large hospitals in SSA and many women die unrecorded outside hospital.

\section{PERIPARTUM STERILISATION IS MUCH MORE EFFECTIVE AND ECONOMICAL THAN AVAILABLE ALTERNATIVES INCLUDING INTERVAL TO}

The chance of a pregnancy after a peripartum TO is low: around $0.75 \%$ in total over the following 10 years. ${ }^{34}$ A prospective study conducted in Uganda and Zimbabwe found that the 12-month cumulative probability of pregnancy for HIV-uninfected women intending to use oral contraceptives for at least a year was $20 \% .{ }^{35}$ It found similarly defined failure rates of $26 \%$ for condoms and $2.5 \%$ for injectable contraceptives. In other words, in SSA, where 5.5 million unsafe abortions cause 28500 female deaths annually, ${ }^{26}$ - there are perhaps 40 abortion fatalities in the entire 'First World' with a similar population size-contraceptive alternatives for the non-rich result in unintended pregnancies considerably more often in 1 year than 
a peripartum TO in 10 years: 25 times, 35 times and 3 times, respectively.

One often hears the opinion that the high failure rates related to client-controlled contraception (pills, injections, condoms, calendar method, withdrawal) as compared with the 'fit and forget' methods (implants, IUDs) demonstrate that the women involved knowingly or subconsciously want a baby (or an abortion?). While this may happen sometimes, some examples, arguable, show the veracity of this opinion, that is, not using medical prophylaxes or insecticide-treated bed nets means wanting malaria, not taking or collecting one's anti-HIV or antiepilepsy medication reliably is a craving for AIDS or convulsions, not taking folic acid before and during early pregnancy means desiring a child with spina bifida, travelling by SUV to fitness training indicates a desire for the polar ice caps to melt and not refraining from tobacco use is choosing cancer or a growth retarded baby. ${ }^{36}$

Copper intrauterine devices (IUDs), coils, require skilled providers and back-up services. This makes rural community-based provision, as advocated by WHO in LRL for oral contraceptives, condoms and injectables, inappropriate. ${ }^{37}$ Interval (ie, unrelated to delivery, extra uterine pregnancy or miscarriage/abortion) TOs, male sterilisations, IUDs and contraceptive implants are inaccessible to most in LRL. ${ }^{23}$ Moreover, it was recently found in Swaziland that $12.4 \%(15 / 121)$ of women fitted with the otherwise very reliable contraceptive hormonal implant (levonorgestrel $75 \mathrm{mg}, 5$ years effective), for which acute back-up services are unnecessary, became pregnant while using efavirenz, an anti-HIV medication often prescribed in SSA. ${ }^{38}$ Besides, efavirenz might also be teratogenic, that is, should only be given in combination with the most effective contraception.

In practice, for completed families in some LRL and in virtually all high HIV prevalent areas, injectables are-despite much unmet demand-the only realistic option, used by approximately 50 million women globally. ${ }^{14}$ However, moderate to severe hypertension, often seen in women over 40 in SSA, is a relative contraindication for injectables and oral contraceptives. Quite some women suffer from heavy, frequent and/or irregular bleeding when using these injections and discontinue use. Recent developments could spell more problems since there is evidence that hormonal contraceptives, principally 3-monthly injectables, might facilitate horizontal (ie, between sexual partners) HIV transmission. ${ }^{39-41}$ This could alarm potential users and their partners and reactivate anti-injectables campaigners (who have no idea how it is to run a family on $\$ 1.25$ per person per day), even though in general reliable hormonal contraception prevents far more problems than it causes. ${ }^{39-41}$

Consequently, for women with assuredly completed families or obvious medical indications, peripartum TOs are vastly superior: resupply is unnecessary and CS/TOs have no known contraindications and virtually no side-effects. CS/TOs and VD/TOs have anyway lower failure rates than interval TOs-overwhelmingly so if compared on an intention-to-have-no-more-pregnancies basis, that is, if one contrasts women permitted to undergo a desired peripartum TO with women who also would like such a TO but are, perhaps because of the Committee's advice, denied that option and encouraged to return weeks or months after delivery to make a TO appointment, join the waiting list and/or raise up to $€ 2000$, as the case may be.

In many LRL it might be possible for low income women to have their (emergency) CS combined with a TO if so desired, but often non-private doctors are too scarce and busy to perform an interval TO. ${ }^{521232427}$ In the private sector, such a TO might cost for the poor as much as 10 years of the monetary family income.
Peripartum, sutures are likely more effective ${ }^{42}$ and certainly more economical than TO clips: a disposable set, clip applicator included, costs $\sim € 450$. Moreover, sutures make it also possible to remove the tubes completely, which probably significantly reduces a woman's lifetime risk of ovarian cancer, ${ }^{43}$ a malignancy with nearly a $100 \%$ mortality in LRL and around $60 \%$ in rich countries. Therefore, if leftover suture material from the uterine closure is used, the optimal CS/TO technique costs nothing. Perversely, in many settings this benefit could form the Achilles' heel of peripartum TOs, since it means this approach is ignored by gadget lovers and not promoted by a commercial lobby. In fact, private obstetricians/hospitals could have an incentive not to provide the peripartum TO option at all since they would often be gainfully involved in the services needed for a woman's contraception and unintended pregnancies for many years to come.

In addition to the high typical failure rates of non-TO contraception available to the non-rich, there are approximately 222 million women (see box 2) with an unmet need for modern contraception. ${ }^{44}$ Many of these women have a completed family -18 million and growing in SSA and 40 million in South Central Asia. ${ }^{27} 44{ }^{45}$ Several million of them delivered the last time by CS.

\section{OTHER PROBLEMS WITH THE COMMITTEE'S REPORT FIGO condemns medically indicated emergency CS/TOS}

Consider an unbooked 38-year-old pregnant woman who has already delivered four times who is lucky to be still alive at admission after three eclamptic episodes (life-threatening seizures in pregnancy related to high blood pressure, very likely, in the absence of sophisticated supervision facilities, to kill in following pregnancies) that started $18 \mathrm{~h}$ earlier; or a woman with a similar reproductive background who needs a classical (ie, vertical, which results in a weak scar) uterine incision for a neglected transverse lie of the foetus; or who is suffering from a uterine rupture. In such scenarios, even many Mothers Superior in Catholic hospitals have 'allowed' CS/TOs for some 25 years, recently not even bothering to hide them from the bishops. Women who had a medical TO indication more often regret ending their reproductive career, however, most blame the medical indication, not the TO. Conversely many women are very happy with a medical excuse to stop having children.

If these TOs are not allowed, doctors, expecting their patient to die if there is another pregnancy, might (and perhaps should?) easily discover/trump up during the operation an acute lifesaving excuse to remove the uterus: same effect on fertility, more grateful patient, more heroic dangerous operation, especially if performed by a non-specialist under basic circumstances. This is not a flight of fancy. Hysterectomies - by a private gynaecologist-performed instead of an interval TO were (and still are at places) routine in Catholic hospitals for the richer women of the First World, Philippines and Latin America. Characteristically, a concocted medical indication (eg, very heavy painful periods), the result of a 'conspiracy' between patient and doctor, served as excuse so as not to offend the church or even the law. No doubt, this results in senseless mortality and morbidity.

Imagine a 37-year-old woman in labour in a well-equipped and staffed Doctors-Without-Borders emergency hospital which happened to be placed near her home. She has delivered earlier, not so easily, five times at home, now there is a full civil war. The doctors detect 'foetal distress'. They think there might be a 10\%-30\% chance the baby will be damaged or die before it is born. On the other hand, with the uncertain political situation and infrastructure, it can easily be that her chance of dying from a scar in the 
uterus during delivery the next time is around 25\%, and the probability that she has continuous access to reliable reversible contraception for the next 13 years is zero. If she would agree to a CS/ $T O$, this would solve the quandary. Is it really unethical to ask her?

The Committee advises doctors to attend to contraception later, 'even if a future pregnancy may endanger a woman's life'.

A sterilisation is, for technical medical reasons, inadvisable within a few months of a CS while non-breastfeeding women might easily become pregnant during that time. Moreover, intra-abdominal adhesions occur frequently, particularly in LRL where CSs are often associated with prolonged rupture of membranes, hampered aseptic precautions and a lack of antibiotics. These infections can also weaken the uterine scar, which may rupture in a subsequent pregnancy even without contractions. The adhesions make interval TOs-if, as the Committee advises, 'contraception is attended to later' and if this procedure is available at all-much riskier than peripartum TOs are. This while the dependable alternatives, that is, long acting reversible contraceptives, are used by only $0.9 \%$ of couples in SSA (compared with $14.6 \%$ globally and $18.3 \%$ in Asia). ${ }^{14}$ As these implants and IUDs become more commonly available and interval TOs and vasectomies are increasingly covered by insurance, also in rich countries, providing the peripartum TO option (belatedly) will become less essential.

The Committee states that, as long as counselling was not first offered close to the end of a pregnancy: 'sterilization should be made available to any person of adult age; no minimum or maximum number of children may be used as a criterion for access."

In most settings, this 'any' will undermine staff and community support for perinatal TO. Youth is consistently correlated with regretted TOs and in the Dutch study ${ }^{6}$ described above, only $12(2.9 \%)$ of the 418 respondents who favoured routine antenatal CS/TO counselling thought the issue should be raised during a woman's first pregnancy-this in a country where women deliver 1.8 children, on average, as opposed to 7.0 children in Niger, 6.0 in Uganda, Eritrea 4.7 and 4.3 in Yemen.

FIGO does not provide ethical guidance for situations that commonly confront doctors

A women aged (say) 38 years who has had no previous TO counselling, who has already delivered 1-8 times vaginally, who seems well informed and who is supported by her partner (who could, however, be trying to evade a feared promised vasectomy), requests a $\mathrm{TO}$ en route to the theatre for an unscheduled CS. Some obstetricians would refuse under these circumstances, others would comply. FIGO's advice does not help them.

Nor does FIGO offer guidance about performing a longagreed CS/TO when the child is born in poor condition, prematurely or seems to have unanticipated abnormalities of yet unknown significance. Could the doctor propose (most women are awake during a CS but have no pain) not to perform the arranged TO, or does the Committee think it always unethical to give women a choice around the time of delivery?

What, moreover, does FIGO recommend for women who have not received TO counselling, and are admitted in early labour with a history of three to four previous CSs? This occurs even in Europe, where unregistered refugees, who could be repatriated later to LRL with poor medical infrastructures, unpredictably show up at hospitals late in pregnancy. It appears seriously unethical not to inform such women about the compounded serious risks of further CSs and advise them as to the most rational course to take, that is, CS/TO.

What to do if patients have attended antenatal care in health institutions where only 'natural' or 'complete abstinence' family planning is supported and TO counselling forbidden, but have been referred elsewhere late in pregnancy?

This happens in the USA, ${ }^{7} 4647$ the Philippines, ${ }^{22}$ Latin America and frequently in rural Africa where two-thirds of the SSA population live. Does the Committee's recommendation against belated TO counselling still apply if referring establishments have deliberately ignored its advice to counsel pregnant women early? These referring health institutions will, of course, also fail to assist a woman with 'sinful' modern contraception after she has returned from delivery bearing a scar in her uterus, although often they are the only health facility for miles around.

In rich countries, Catholic contraception doctrines are mostly inconvenient, guilt provoking and expensive. In rural Africa, Latin America and the Philippines, they kill. What does the Committee think of the situation, prevalent in SSA and the Netherlands, in which obstetricians refuse a desired CS/TO to a mother of 1-4 who is referred by her midwife while in labour because an unexpected CS seemed indicated, even when assured by the midwife, the patient and her partner that there was an early, proper 'suppose you need a CS...' discussion, because the obstetrician did not perform that counselling herself ? $^{18}$

Furthermore, there are women who do not want to discuss VD/TO early, in the spirit of 'Don't count your chickens...', for reasons of superstition or because they want to know if it is a boy or a girl, but who are nevertheless very keen to have a VD/ TO once the VD is out of the way. Would the Committee prefer to send them home without the sterilisation they want?

In Papua New Guinea (PNG), women who have decided that their family is complete after their current pregnancy sometimes travel long distances to a hospital just before they are due, 'demonstrating the strength of their motivation and the depth of their resolution', in order to access a VD/TO (personal communication, Professor Glen Mola, PNG). Is not refusing such women a sterilisation procedure because there was no counselling earlier in the pregnancy patronising, if not unethical? In the public medical system in PNG, about $25 \%$ of all CS are combined with a TO, but there is also a rather isolated hospital administrated by very orthodox protestant US doctors where this is $4 \%$. One wonders which figure is likely to represent the highest ethical standards.

If the Committee deems women around the time of delivery not qualified to choose a CS/TO or VD/TO, then, arguably, it should declare it at least as unethical to strongly discourage women who decided earlier to have a TO. The consequences of the discouraging, which occurs very frequently, are at least as dramatic but nobody is reprimanded or sued, ${ }^{1822} 244647$ which could be related to an atavistic fertility bias.

\section{DISASTERS WAITING TO HAPPEN}

In areas vulnerable to earthquakes, floods, strikes, civil wars (perhaps with raping soldiers), logistical failures, economic collapse, unreliable or non-existent implant or IUD donors and contraceptive scares, uterine scars in women who did not have a TO are akin to landmines-they may explode many years down the line, for example, in a woman who is 48 years. An attack by 'M23' forced 285000 people to flee their homes in East Congo, and healthcare providers were abducted and killed. ${ }^{48}$ There were catchment-area-based CS rates in that region of around $10 \%$ in previous years. The hospital in Garissa, northeast Kenya, was also recently depleted of health staff following attacks by armed men believed to originate from Somalia, while the doctors had scarred uteri for years, thinking it unethical to ask unbooked mothers of many children whether they would like a TO with their CS. One justification was that husbands like 
having many children (sons in fact), attitudes hardly in line with the Committee's declared position on female autonomy. ${ }^{1}$ An even more desperate situation prevails in South Sudan, Mali and the Central African Republic. No doubt the 'Arab Spring' also interferes with access to properly supervised labour and access to contraception. What will happen to Afghani women with a scarred uterus? Indeed, presently even in Kabul, with an estimated 70000 street kids, it is nearly impossible for the average woman to source simple oral contraceptives, let alone a more reliable method which would involve a male doctor touching her. Only 13\% of the deliveries in Afghanistan are presently attended by skilled health professionals and one in 50 women die of a pregnancy. In the future, depending on how political conditions develop, contraceptive providers may be killed, in the manner of at least 12 polio vaccinators in Pakistan and nine in Northern Nigeria. ${ }^{49}$

\section{ABORTION}

It seems, see quotations in the Introduction section of this paper, that FIGO's Ethical Committee considers it always unethical to combine a TO with a termination of pregnancy, and probably also with the treatment of the complications arising from a miscarriage or 'backstreet' abortion. ${ }^{1}$ This blanket recommendation is not well considered: there are so many different circumstances in the world. What if a 39-year-old woman with a completed family, who cannot cope reliably with the unreliably available reversible contraceptives, is seen repeatedly in hospital after a 'backstreet' abortion and this time has to be operated anyway for a hole in the uterus, while she is very eager to have a TO? I have often attended to such women. A review in the Netherlands published in 1980 of 1000 laparoscopic TOs, of which 140 were combined with a termination of pregnancy, found that after a median follow-up of 2 years (somewhat early to evaluate the regret rate), only one woman of the 1000 regretted her TO. ${ }^{50}$ It is all in the quality of counselling, the ethical standards of the healthcare providers and the incidence of serious non-anticipatable events. Moreover, there are many countries with a mandatory reflexion period of days after an abortion request, so then there is some time to reflect on a TO. The Committee is of course right if it means that abortion provision should not be conditional on TO consent, and moreover there are studies with a much higher incidence of regret. However, I am not aware of the existence of cohort studies with long-term follow-up of women, of say over 35 years of age, who did or did not receive after proper counselling, the option to combine their abortion with a TO: the only fair evaluation. However, such a study does still not answer the question what is worse: a regretted TO or many more unintended pregnancies? Sterilisation in combination with an abortion was studied recently with the following conclusions for the USA: 'Prohibiting tubal occlusion at time of abortion resulted in an increased incidence of unintended pregnancy and increased public costs. ${ }^{51}$ There is no evidence that properly counselled women who have a TO with an abortion have more often regrets than women who have an interval TO. ${ }^{51}$

\section{CONCLUSIONS}

Even with very adequate counselling performed long before implementation, there will be women who regret a sterilisation. Marriages break up, children and partners can die, feelings change. On the other hand, there are millions of women who had wanted to put a stop to their fertility earlier who become pregnant against their will because the barriers between them and the for them best contraception were too high. These unintended pregnancies can be very unsettling, and moreover dangerous without good medical supervision, especially if there is a scar in the uterus or when the women involved have a high parity and/or are above 40 years. In SSA, (rising) national CS rates vary from $0.4 \%$ to $21 \%$; in Asia, they are often higher (see box 2). In any case, only a small group of women can opt for a CS/TO. This group would be much smaller still if the unqualified recommendations of FIGO's Committee that it is better not to counsel about TO at all than to counsel around the time of delivery were adhered to. Importantly, there is very little risk that a sterilisation after a VD is performed without proper understanding and cooperation of a woman. Women do not allow (and nurses will refuse to cooperate), let alone pay, doctors to open their abdomen after a delivery without strong motivation, and there is no evidence whatsoever that there is more often regret if such a sterilisation was first discussed after delivery.

Doctors should always consider whether the costs of not offering the TO option are likely to outweigh the possible but unproven additional risk of TO regret after belated, as compared with early, TO counselling.

Does the prevention of one maternal death justify 10 regretted TOs? Or should the scales tip at one for one, or 10 for one? The calculations presented in this paper pertaining to a not-so-very-poor-resourced location suggest that the latter rate can be a realistic one for women with three or more children (see box 1). In most rich countries, however, maternal mortality is so rare and reliable contraception so available and abortion so risk-free that thousands of extra TOs would be needed to prevent one maternal fatality. On the other hand, in those regions, after serious regret, an IVF pregnancy is an option and it costs a fraction of the expenses of raising a child. Therefore, some more regrets could be acceptable in exchange for many fewer unintended pregnancies.

The calculations in this paper are biased and confounded. Moreover, rationalisations might play a part in the low TO regret rates detected, but the same psychological mechanism can also diminish the regret rates of women who were not sterilised, if they survived. Especially if they had another child they learnt to love. However, the calculations in box 1 provide a firmer base for ethical advice than sweeping armchair theoretical considerations alone. I believe that it is often unethical not to neutrally offer a CS/TO or $\mathrm{VD} / \mathrm{TO}$, where necessary late in pregnancy or soon after a VD, when a mature woman already has children and when the doctor both genuinely believes that providing the TO option is in the patient's best interest and would, in the case of CS/TO, receive no financial benefit from the TO component of this operation. Additional research in diverse settings would be welcome to compare long-term outcomes for women and their families who receive no TO counselling with those who obtain belated counselling. The onus for conducting this is on FIGO's Committee because one must present good reasons to refuse women a potentially life-saving say in such matters. In regions where unbooked deliveries are rare, reversible reliable contraceptive alternatives affordable, interval TOs and vasectomies easily obtainable and abortions safe and accessible, the Committee's stipulation that a peripartum TO should have been discussed earlier in pregnancy seems appropriate, once such counselling becomes an established reproductive right.

Acknowledgements I would like to thank Dr Ivica Music, Dr Anthony Mthombeni and Dr Abdulkadir Mohmed Wagley for the many patients they counselled and the many operations they performed, and the late Medical Superintendent of United Bulawayo Hospitals, Dr Godwin Gwisai for his support, wisdom and trust. 


\section{Competing interests None.}

Provenance and peer review Not commissioned; externally peer reviewed.

Open Access This is an Open Access article distributed in accordance with the Creative Commons Attribution Non Commercial (CC BY-NC 3.0) license, which permits others to distribute, remix, adapt, build upon this work non-commercially, and license their derivative works on different terms, provided the original work is properly cited and the use is non-commercial. See: http://creativecommons.org/ licenses/by-nc/3.0/

\section{REFERENCES}

1 Dickens B. Female contraceptive sterilisation: International Federation of Gynecology and Obstetrics (FIGO) Committee for the Ethical Aspects of Human Reproduction and Women's Health. Int J Gynaecol Obstet 2011;115:88-9.

2 Pollach G. Anaesthetic-related mortality in sub-Saharan Africa. Lancet 2013;381:199.

3 Bashford T. Anaesthesia in Ethiopia: providers' perspectives on the current state of the service. Trop Doct 2014:44:6-13.

4 Kozhimannil KB, Law MR, Virnig BA. Cesarean delivery rates vary tenfold among US hospitals; reducing variation may address quality and cost issues. Obstet Gynecol Surv 2013;68:499-501.

5 Verkuyl DA. Sterilisation during unplanned caesarean sections for women likely to have a completed family — should they be offered? Experience in a country with limited health resources. BJOG 2002;109:900-4.

6 Verkuyl DA, van Goor GM, Hanssen MJ, et al. The right to informed choice. A study and opinion poll of women who were or were not given the option of a sterilisation with their Caesarean Section. PLOS ONE 2011;6:e14776. http://www. plosone.org/article/info\%3Adoi\%2F10.1371\%2Fjournal.pone.0014776

7 Borrero S, Zite N, Creinin MD. Federally Funded Sterilisation: Time to Rethink Policy? Am J Public Health 2012;102:1822-5.

8 Potter JE, White K, Hopkins K, et al. Frustrated Demand for Sterilisation Among Low-Income Latinas in El Paso, Texas. Perspect Sex and Reprod Health 2012;44:228-35.

9 Borrero S, Zite N, Potter JE, et al. Medicaid Policy on Sterilization - Anachronistic or Still Relevant? N Engl J Med 2014;370:102-4.

10 Soares LC, Brollo JLA. Family planning in Brazil: why not tubal sterilisation during childbirth? J Med Ethics 2013;39:710-12.

11 United Nations. The Millennium Development Goals Report 2011. New York: United Nations, 2011

12 Igberase GO, Ebeigbe PN, Umeora O, et al. Bilateral tubal ligation in a rural hospital in the Niger Delta, Nigeria. Niger J Clin Pract 2011;14:137-9. http://www. njcponline.com/text.asp?2011/14/2/137/84001

13 Chigbu CO, Onyebuchi AK, Onwudiwe EN, et al. Denial of women's rights to contraception in southeastern Nigeria. Int J Gynaecol Obstet 2013;121:154-6. http://dx.doi.org/10.1016/j.ijgo.2012.12.010 (accessed 24 May 2014).

14 United Nations, Department of Economic and Social Affairs-Population Division. World contraceptive use, 2011. http://www.un.org/esa/population/publications/ contraceptive2011/wallchart_front.pdf (accessed 24 May 2014).

15 Jones J, Mosher W, Daniels K. Current contraceptive use in the United States, 2006-2010, and changes in patterns of use since 1995. National health statistics reports, No 60. Hyattsville, MD: National Center for Health Statistics. 2012. http:/l www.cdc.gov/nchs/data/nhsr/nhsr060.pdf (accessed 24 May 2014).

16 Cox Macpherson C. Climate change matters. J Med Ethics 2014;40:288-90.

17 Bhutta ZA, Black RE. Global maternal, newborn, and child health - so near and yet so far. N Engl J Med 2013;369:2226-35.

18 Verkuyl DAA. "Mevrouw, there is more regret and failure following a sterilization together with a caesarean, and all those hormones in pregnancy preclude rational judgement". Eur J Obstet Gynecol Reprod Biol 2014. doi:10.1016/j. ejogrb.2014.04.027

19 Murtaugha PA, Schlax MG. Reproduction and the carbon legacies of individuals. Global Environ Change 2009;19:14-20.

20 Hardin G. The Tragedy of the Commons. Sci New Ser 1968;162:1243-48. http:/l www.geo.mtu.edu/ asmayer/rural_sustain/governance/Hardin\%201968.pdf (accessed 24 May 2014).

21 Gaym A. Current and future role of voluntary surgical contraception in increasing access to and utilization of family planning services in Africa. Ethiop Med J 2012:50:363-70.

22 Gulland A. Law to broaden access to contraception gets green light in Philippines. BMJ 2014:348:g2725. http://dx.doi.org/10.1136/bmj.g2725

23 Morse J, Chipato T, Blanchard K, et al. Provision of long-acting reversible contraception in HIV-prevalent countries: results from nationally representative surveys in southern Africa. BJOG 2013;120:1386-94.

24 Verkuyl DAA. Tubal ligation candidates who did not get their operation. Cent Afr $J$ Med 1996:42:150-2.

25 Verkuyl DAA, Commentary. Intention to treat studies crucial for contraception research. Contraception 2009:80:234-6.
26 WHO. Safe abortion: technical and policy guidance for health systems - 2nd ed. Geneva 2012. ISBN 9789241548434 http://apps.who.int/iris/bitstream/10665/ 70914/1/9789241548434_eng.pdf

27 Bradley SEK, Croft TN, Fishel JD, et al. Revising unmet need for family planning. DHS analytical studiesno. 25, 2012. ICF International, Calverton, Maryland, USA. http://dhsprogram.com/publications/publication-as25-analytical-studies.cfm

28 Rutstein S, Winter R. The Effects of Fertility Behavior on Child Survival and Child Nutritional Status: Evidence from the Demographic and Health Surveys, 2006 to 2012. DHS analytical studies no. 37, 2014. ICF International, Rockville, Maryland, USA. http://www.dhsprogram.com/pubs/pdf/AS37/AS37.pdf

29 UNAIDS. World AIDS Day Report, 2012. Geneva, Switzerland: UNAIDS 2012. http:/ www.unaids.org/en/media/unaids/contentassets/documents/epidemiology/2012/ gr2012/JC2434_WorldAIDSday results en.pdf (accessed 24 May 2014).

30 WHO. Prevention of mother-to-child transmission of HIV and family planning. http:/l www.who.int/reproductivehealth/topics/linkages/pmtct/en/ (accessed 15 Mar 2014).

31 Kassebaum NJ, Bertozzi-Villa A, Coggeshall MS, et al. Global, regional, and national levels and causes of maternal mortality during 1990-2013: a systematic analysis for the Global Burden of Disease Study 2013. Lancet Published online May 2, 2014. http://dx.doi.org/10.1016/S0140-6736(14)60696-6

32 Verkuyl DAA. Family planning in Zimbabwe in the nineties. Centr Afr J Med 1991:37:308-16.

33 Hancock B. Vesico-vaginal and recto-vaginal fistula. In: Van Beekhuizen $\mathrm{H}$ Unkels R, eds. Textbook of gynecology for less-resourced locations. London: Sapiens Publishing, 2012:233-74. http://www.glowm.com/resource_type/resource/textbook/ title/a-textbook-of-gynecology-for-less-resourced-locations/resource_doc/35 (accessed 24 May 2014).

34 Peterson HB, Xia Z, Hughes JM, et al. The risk of pregnancy after tubal sterilization: findings from the U.S. Collaborative Review of Sterilization. Am J Obstet Gynecol 1996;174:1161-8.

35 Steiner MJ, Kwok C, Dominik R, et al. Pregnancy risk among oral contraceptive pill, injectable contraceptive, and condom users in Uganda, Zimbabwe, and Thailand. Obstet Gynecol 2007;110:1003-9.

36 Tran DT, Roberts $C L$, Jorm LR, et al. Change in smoking status during two consecutive pregnancies: a population-based cohort study. BJOG 2014 Published online: 16 APR 2014. doi:10.1111/1471-0528.12769

37 Verkuyl DAA. Contraception. In: Van Beekhuizen H, Unkels R, eds. Textbook of gynecology for less-resourced locations. London: Sapiens Publishing, 2012:147-69. http://www.glowm.com/resource_type/resource/textbook/title/a-textbook-ofgynecology-for-less-resourced-locations/resource doc/35 (accessed 24 May 2014).

38 Perry SH, Swamy P, Preidis GA, et al. Implementing the Jadelle implant for women living with HIV in a resource-limited setting in sub-Saharan Africa: concerns for drug interactions leading to unintended pregnancies. AIDS 2014;28:791-3.

39 Giles SL, Lester F. Should women with HIV, or at high risk of contracting HIV, use progestogen-containing contraception? BMJ 2013:347:f6695.

40 Jain AK. Hormonal contraception and HIV acquisition risk: implications for individual users and public policies. Contraception 2012;86:645-52.

41 Rodriguez M, Reeves M, Caughey A. Evaluating the competing risks of HIV acquisition and maternal mortality in Africa: a decision analysis. BJOG 2012;119:1067-73.

42 Rodriguez MI, Seuc A, Sokal DC. Comparative efficacy of postpartum sterilisation with the titanium clip versus partial salpingectomy: a randomised controlled trial. BJOG 2013;120:108-12.

43 Blake Gilks C, Miller D. Opportunistic salpingectomy for women at low risk for development of ovarian carcinoma: The time has come. Gynecol Oncol 2013:129:443-4. http://dx.doi.org/10.1016/j.ygyno.2013.04.021

44 Gribble JN. Unmet need for contraception: Fact sheet. Washington, DC: Population Reference Bureau, 2012. http://www.prb.org/Articles/2012/unmet-need-factsheet. aspxhttp://www.prb.org/Publications/Datasheets/2012/world-population-data-sheet/ fact-sheet-unmet-need.aspx (accessed 24 May 2014).

45 Alkema L, Kantorova V, Menozzi C, et al. National, regional, and global rates and trends in contraceptive prevalence and unmet need for family planning between 1990 and 2015: a systematic and comprehensive analysis. Lancet 2013;381:1642-52

46 Stulberg DB, Hoffman Y, Hasham Dahlquist I, et al. Tubal Ligation in Catholic Hospitals: A Qualitative Study of Ob-Gyns' Experiences. Contraception 2014. doi:10.1016/j.contraception.2014.04.015

47 American Civil Liberties Union. Miscarriage of medicine: The growth of Catholic hospitals and the threat to reproductive health care. ACLU, New York, 2013. https://www.aclu.org/files/assets/growth-of-catholic-hospitals-2013.pdf (accessed 24 May 2014).

48 News Analysis. U.N. ambassador questioned on U.S. role in Congo violence. New York Times 9 December 2012

49 Gunmen kill Nigerian polio vaccine workers in echo of Pakistan Attack. New York Times 8 February 2013.

50 Eskes M. Laparoscopische Sterilisatie. Ned Tijdschr Geneeskd 1980;124:729-34.

51 Krashin JW, Edelman AB, Nichols MD, et al. Prohibiting consent: what are the costs of denying permanent contraception concurrent with abortion care? 
Am J Obstet Gynecol 2014;211:76.e1-10. http://dx.doi.org/10.1016/j.ajog.2014. 04.039

52 Thurman AR, Janecek T. One-year follow-up of women with unfulfilled postpartum sterilization requests. Obstet Gynecol 2010;116:1071-7.

53 Peterson HB, Darmstadt GL, Bongaarts J. Meeting the unmet need for family planning: now is the time. Lancet 2013;381:1696-9.
54 Ologunde R, Vogel JP, Cherian MN, et al. Assessment of caesarean delivery availability in 26 low- and middle-income countries: a cross-sectional study. Am J Obstet Gynecol 2014. doi:10.1016/j.ajog.2014.05.022.

55 UNPD. World Population Prospects: The 2012 Revision http://esa.un.org/unpd/wpp/ unpp/panel_population.htm (accessed 28 June 2014). 